\title{
PREVALENCE OF ANAEMIA IN PREGNANT WOMEN- A SINGLE INSTITUTION STUDY WITH SPECIAL REFERENCE TO RURAL AREA OF NORTH INDIA
}

\author{
Minakeshi Rana1, Virender Mohan Rana², Narinder Singh Bhutyal³, Surinder Kumar Atri4 \\ ${ }^{1}$ Consultant, Department of Obstetrics and Gynaecology, CHC Jourian, Akhnoor, J \& K Health Services, Jammu, Jammu and Kashmir, \\ India. \\ 2Medical Officer, DH Rajouri, J \& K Health Services, Jammu, Jammu and Kashmir, India. \\ 3Block Medical Officer, Akhnoor, J \& K Health Services, Jammu, Jammu and Kashmir, India. \\ ${ }^{4}$ Assistant Professor, Department of Pathology, Government Medical College, Jammu, Jammu and Kashmir, India.
}

\section{ABSTRACT}

\section{BACKGROUND}

Anaemia is the commonest medical disorder in pregnancy. In developing countries, anaemia contributes to $40-60 \%$ of all maternal deaths directly or indirectly. ${ }^{1,2}$ In India $16 \%$ of all maternal deaths are directly due to anaemia. ${ }^{3}$ Anaemia is associated with an increase in incidence of preterm birth, IUGR and low Apgar at birth with resultant increase in perinatal morbidity and mortality. Anaemia is more common in developing countries as compared to developed countries. Therefore, we planned this study to evaluate the prevalence of anaemia in pregnant women

\section{MATERIALS \& METHODS}

A cross sectional study to determine the prevalence and severity of anaemia was done on pregnant women attending antenatal clinic at Community Health Centre Jourian, Akhnoor, Jammu. All pregnant women (300) who attended the antenatal clinic from July 2011 to December 2011 were included in the study. Haemoglobin was estimated by Sahli's method and anaemia was graded according to ICMR criteria. Anaemia and its severity were correlated with different age groups, gravida and dietary habits.

\section{RESULTS}

The women were 15-35 years of age. Maximum no. of patients 53.3\% $(n=160)$ were in the age group of 21-25 years followed by $30.8 \%(\mathrm{n}=92), 10.696(\mathrm{n}=32), 5.3 \%(\mathrm{n}=16)$ in age groups of 26-30 years, 15-20 years and 31-35 years respectively. Maximum number of patients $46.6 \%(n=140)$ were primigravida, $30 \%(n=90)$ were gravid $2,20 \%(n=60)$ gravid $3,2.6 \%(n=8)$ were gravid 4 and $0.6 \%(n=2)$ were gravid $5.93 \%$ women were anaemic, $63 \%$ had moderate anaemia, $27 \%$ had mild anaemia and $3 \%$ had severe anaemia. 95\% women were pure vegetarian and 5\% non-vegetarian. Prevalence of anaemia increased as parity increased. 58.1\% anaemia was seen in patients who had pregnancy gap of less than 2 years and $41.9 \%$ in patients who had pregnancy gap of more than 2 years.

\section{CONCLUSION}

In view of the high prevalence of anaemia in pregnancy and serious adverse consequences in both mother and baby, management of anaemia in pregnancy should be accorded a high priority both in obstetric and public health practice.

\section{KEY WORDS}

Anaemia, Pregnant Females, Prevalence, Rural Area.

HOW TO CITE THIS ARTICLE: Rana M, Rana VM, Bhutyal NS, et al. Prevalence of anaemia in pregnant women- a single institution study with special reference to rural area of North India. J. Evolution Med. Dent. Sci. 2019;8(06):373-376, DOI: $10.14260 /$ jemds/2019/82

\section{BACKGROUND}

Anaemia is the commonest medical disorder in pregnancy. In developing countries anaemia contributes to $40-60 \%$ of all maternal deaths directly or indirectly. ${ }^{1,2}$ In India $16 \%$ of all maternal deaths are directly due to anaemia. ${ }^{3}$ Anaemia is associated with an increase in incidence of preterm birth, IUGR and low Apgar at birth with resultant increase in perinatal morbidity and mortality- Anaemia is more common in developing countries as compared to developed countries, it is estimated that all over the world about 500 million women in

'Financial or Other Competing Interest': None.

Submission 10-01-2019, Peer Review 30-01-2019,

Acceptance 01-02-2019, Published 11-02-2019.

Corresponding Author:

Dr. Surinder Kumar Atri,

Associate Professor,

House No. 24, Lane 51, Behind Sunny Farms,

Greater Kailash Post Office,

Gangyal, Jammu, Jammu and Kashmir, India

E-mail: surinderkumaratri@gmail.com

DOI: $10.14260 /$ jemds/2019/82

\section{(c) (1) $(9)$}

reproductive age group are anaemic. ${ }^{4}$ As per WHO estimates

$56 \%$ of all women in developing countries are anaemic. ${ }^{5}$

In India, National Family Health Survey (NFHS-3) in 20052006 has shown that $55 \%$ of Indian women are anaemic 6 whereas in USA only 2-4\% women are anaemic. ${ }^{7}$

The prevalence of anaemia is further increased in pregnancy. It ranges between $50-90 \%$ in developing countries and 18$20 \%$ in developed countries. According to NFHS-3, 59\% of pregnant women are anaemic. ${ }^{6}$ In India, a Steering Committee report has shown that $13 \%$ of pregnant women have a haemoglobin level of less than $5 \mathrm{gm} \%$ and $34 \%$ have value less than 8 gm $\% .^{8}$

Anaemia is defined as a condition when the circulating levels of haemoglobin qualitatively or quantitatively are lower than the normal. The criteria for defining anaemia is shown in Table I.

Anaemia is also graded as per severity as mild, moderate and severe, Indian Council of Medical Research (ICMR) criteria for defining the severity of anaemia is given in Table II. 


\begin{tabular}{|c|c|}
\hline Non-Pregnant Women & $\mathrm{Hb}<12 \mathrm{gm} \%$ \\
\hline Pregnant Women [WHO] ${ }^{9}$ & $\mathrm{Hb}<11 \mathrm{gm} \%$ \\
\hline Pregnant Women $[C D C]^{10}$ & $\begin{array}{c}\mathrm{Hb}<11 \text { gm } \% \text { (1 \& III Trimester) } \\
\mathrm{Hb}<10.5 \mathrm{gm} \% \text { (II Trimester) }\end{array}$ \\
\hline \multicolumn{2}{|c|}{ Table I. Criteria for Defining Anaemia } \\
\hline
\end{tabular}

\begin{tabular}{|c|c|}
\hline Severity of Anaemia & Haemoglobin Level \\
\hline Mild & $10-10.9 \mathrm{gm} \%$ \\
\hline Moderate & $7-9.9$ gm $\%$ \\
\hline Severe & $<7$ gm $\%$ \\
\hline Very Severe & $<4 \mathrm{gm} \%$ \\
\hline \multicolumn{2}{|c|}{$\begin{array}{l}\text { Table II. Classification of Anaemia According to } \\
\text { Severity [ICMR]11 }\end{array}$} \\
\hline
\end{tabular}

\section{MATERIALS AND METHODS}

A cross sectional study was conducted on 300 pregnant women attending antenatal clinic at Community Health Centre Jourian, A Khnoor, Jammu w. e. f. July 2011 to December 2011. The data was collected by personal interview using a pretested questionnaire and haemoglobin was estimated by Sahlis method. Anaemia was graded according to the criteria given by ICMR. ${ }^{11}$ Sahlis method is the most commonly used method for estimation of haemoglobin, here a derivative formed is acid haematin which is brown in colour and its colour is matched against standard brown tinted glass in comparator by direct vision and reading taken as gm of $\mathrm{Hb} / 100 \mathrm{ml}$ of blood. It is based on the principle that $\mathrm{Hb}$ in RBC in a given sample of blood is converted into a derivative of $\mathrm{Hb}$ and colour of the derivative is matched against a standard colour by direct vision.

\section{Sampling Technique}

Convenience sampling.

\section{RESULTS}

In the study population of 300 pregnant women, the women were 15 -35 years of age, $10.6 \%(n=32)$ were in the age group of $15-20$ years, $53.3 \%(n=160)$ were in the age group of $21-25$ years, $30.8 \%$ were in the age group of $26-30$ years $(n=92)$ and $5.3 \%(n=16)$ were in the age group of $31-35$ years. Maximum number of anaemic patients $(n=149)$ were in the age group of 21-25 years and minimum no of anaemic $(n=15)$ patients were in age group of 31-35 years. Maximum number $(n=140)$ of patients were primigravida and very few patients were gravid $4(\mathrm{n}=8)$ and gravid $5(\mathrm{n}=2) .93 \%$ of the women of the study group were anaemic, $63 \%$ had moderate anaemia, $27 \%$ had mild anaemia and $3 \%$ had severe anaemia. $95 \%$ of the women of study group were pure vegetarian and $5 \%$ non- vegetarian. Prevalence of anaemia was found to be more (58.1\%) among women with an interval of 1-2 years between pregnancies followed by women with an interval of $2-3$ years $(41.9 \%)$. Another interesting finding of the study was that most of women in study group were vegetarian (95\%) whereas only $5 \%$ were non-vegetarian.

\begin{tabular}{|c|c|c|c|}
\hline $\begin{array}{c}\text { Age } \\
\text { (Years) }\end{array}$ & $\begin{array}{c}\text { Total No. of } \\
\text { Women }\end{array}$ & $\begin{array}{c}\text { No. Anaemic } \\
\text { Patients }\end{array}$ & $\begin{array}{c}\text { Percentage of } \\
\text { Anaemic Patients }\end{array}$ \\
\hline $15-20$ & 32 & 28 & $87.5 \%$ \\
\hline $21-25$ & 160 & 149 & $93.12 \%$ \\
\hline $26-30$ & 92 & 87 & $94.51 \%$ \\
\hline $31-35$ & 16 & 15 & $93.15 \%$ \\
\hline \multicolumn{4}{|c|}{ Table III. Distribution of Women According to Age } \\
Group and Anaemia \\
\hline
\end{tabular}

\begin{tabular}{|c|c|c|c|}
\hline $\begin{array}{c}\text { Parity } \\
\text { (Gravida) }\end{array}$ & $\begin{array}{c}\text { Total No. } \\
\text { Patients }\end{array}$ & $\begin{array}{c}\text { Anaemic } \\
\text { Patients }\end{array}$ & Prevalence \\
\hline Gravida 1 & 140 & 128 & $92.8 \%$ \\
\hline Gravida 2 & 90 & 84 & $93.3 \%$ \\
\hline Gravida 3 & 60 & 57 & $95 \%$ \\
\hline Gravida 4 & 08 & 08 & $100 \%$ \\
\hline Gravida 5 & 02 & 02 & $100 \%$ \\
\hline Table IV. Distribution of Patients According to Parity and \\
\multicolumn{4}{|c|}{ Anaemia } \\
\hline
\end{tabular}

\begin{tabular}{|c|c|c|}
\hline Severity of Anaemia & No. of Patients & Percentage \\
\hline Mild & 81 & $27 \%$ \\
\hline Moderate & 189 & $63 \%$ \\
\hline Severe & 09 & $03 \%$ \\
\hline Table V. Distribution of patients according to severity of \\
anaemia \\
\hline
\end{tabular}

\begin{tabular}{|c|c|c|}
\hline $\begin{array}{c}\text { Gap Between Pregnancies } \\
\text { (Years) }\end{array}$ & $\begin{array}{c}\text { Anaemia } \\
\text { Status }\end{array}$ & Percentage \\
\hline $1-2$ & 100 & 58.1 \\
\hline $2-3$ & 72 & 41.9 \\
\hline \multicolumn{2}{|c|}{ Gable VI. Distribution of Anaemic Patients According to } \\
Gap Between Pregnancies \\
\hline
\end{tabular}

\section{DISCUSSION}

Anaemia is one of the most common health problems In India. The problem is much more in rural than in urban population.12,13 The present study found high prevalence of anaemia, $93 \%$ in pregnant females. The most common anaemia was of moderate severity $63 \%$, then mild $23 \%$ and severe $3 \%$. While in a study on pregnant and lactating women by K.N. Agarwal et al it was found that $84 \%$ pregnant and $92.2 \%$ lactating women were anaemic with severe anaemia in 9.2 and 7.3 percent respectively. ${ }^{14}$ Virender P. et al in their study on pregnant women found that prevalence of severe anaemia was significantly higher in those with age greater than 25 years, educated till high school or less, nuclear family, no history of abortions and birth interval of greater than 36 months. ${ }^{15}$

Worried about the estimated high prevalence of anaemia in the country five major surveys \{National Family Health Survey 2[NFHS-2],16 National Family Health Survey 3 [NFHS 3],17 District Level household Survey [DLHS],18 Indian Council of Medical Research (ICM R) Micronutrient Survey ${ }^{19}$ and Micronutrient Survey conducted by National Monitoring Bureau $[\mathrm{NNMB}]^{20}$ were undertaken to estimate the prevalence of anaemia in pregnancy. NNMB, DLHS, and ICMR surveys showed that over 70 percent of pregnant women were anaemic NFHS. 2 and 3 reported lower prevalence of anaemia in women and pregnant women as compared to DLHS, NNMB and ICMR Micronutrient Surveys. Data from DLHS showed that prevalence of moderate and severe anaemia was high even among educated and higher income groups. Prevalence of anaemia is high in all States, though there are considerable variations between states in prevalence of moderate and severe anaemia. In India, a Steering Committee report has shown that $13 \%$ of pregnant women have a haemoglobin level of less than $5 \mathrm{gm} \%, 34 \%$ have less than $8 \mathrm{gm} \%{ }^{8}$ and anaemia is a common cause of maternal morbidity and mortality and a key factor related to low birth weight. In 1990, the Government of India estimated that 19\% of maternal deaths 
were related to anaemia and India contributes to about $80 \%$ of maternal deaths due to anaemia in South Asia. ${ }^{21}$

Significant association between parity index and prevalence of anaemia as found in the present study calls for measures to limit the number of births by improving the family planning services in rural areas. This may be related to the effect of early marriages and early childbearing. This practice is very prevalent in rural India. Therefore, the results of present study underlie the need for preventing early marriages and the consequent high adolescent pregnancies in India, particularly in high prevalence states Bihar and Andhra Pradesh. This will help to improve nutritional status and health care utilisation among women, thereby prevent maternal and child mortality. ${ }^{22}$ High prevalence of anaemia found in this study may be because $95 \%$ of women were pure vegetarian. The vegetarian diet contains large amount of pulses and less of green leafy vegetables. There is further reduction of folic add due to prolonged cooking. During pregnancy vitamin B12 is actively transported from placenta to foetus, vitamin B12 is found in foods of animal origin like meat, fish, eggs and milk and not destroyed by heating. The daily requirement of vitamin is easily met by non- vegetarians. However, in strict vegetarians, vitamin B12 deficiency may be there.

The main purpose of this study was to find the prevalence of anaemia in pregnancy in rural area Hospitals PHCs, CHCs. Categorize these anaemic patients according to severity, treat them with oral haematinics or injectables and refer patients with severe anaemia to tertiary care Institutes to prevent maternal morbidity and mortality. Taking into account the high prevalence of anaemia in Indian women and its direct and indirect influence on perinatal outcome, FOGSI recommends that all women should be screened for anaemia during pregnancy at the first antenatal visit. Women seeking prenatal consultation or consultation for any other conditions should be screened at least for haemoglobin levels. Adolescent girls should also be screened for anaemia whenever they offer opportunity to the clinician. Anaemia begins in childhood, worsens during adolescence in girls and gets aggravated during pregnancy. Screening for anaemia should be undertaken at regular intervals throughout pregnancy taking into account the increased iron requirements during pregnancy and effects of haemodilution.

\section{CONCLUSION}

In view of the high prevalence of anaemia in pregnancy and serious adverse consequences in both mother and baby, management of anaemia in pregnancy should be accorded a high priority both in obstetric and public health practice. All women should be screened for anaemia during pregnancy at the first antenatal visit. Women seeking prenatal consultation or consultation for any other condition should be screened at least for haemoglobin levels. Adolescent girls should also be screened for anaemia whenever they offer opportunity to the clinician.

\section{REFERENCES}

[1] Bhatt R. Maternal mortality in India-FOGSI-WHO Study. J Obstet \& Gynaecol Ind 1997;47:207-14.

[2] Viteri FE. The consequences of iron deficiency and anaemia in pregnancy. Adv Exp Med Biol 1994;352:127-39.
[3] Abou Zahr C, Royston E. Maternal mortality. A global factbook. Geneva: World Health Organization, 1991.

[4] UN Standing Committee on nutrition 5 annual report on the world nutrition situation: Nutrition for improved developmental outcomes. March 2004.

[5] World Health Organization. The prevalence of anaemia in women: a tabulation of available information. $2^{\text {nd }}$ edn. Geneva: WHO, 1992. (WHO/MCH/MSM/92.2)

[6] Kennedy E, Meyers L. Dietary Reference Intakes: development and uses for assessment of micronutrient status of women-a global perspective. Am J Clin Nutr 2005;81(5):1194S-7S.

[7] National Family Health Survey (NFHS 3 3, India. http: www.nfhsindia.ora/NFHS-3\%20Data/ NFHS3\%20NKF/Report.pdf

[8] Report of Steering committee on nutrition for tenth five year plan (2002-2007). Government of India, Planning commission. Micronutrient deficiencies. Sept 2002;75107.

[9] WHO, Iron deficiency anaemia: assessment, prevention and control. WHO/NHD/01.3, Geneva, 2001.

[10] Centre for Disease Control (CDC). Criteria for anaemia in children and childbearing-aged women. MMWR 1989;38(22):400-4.

[11] Indian Council of Medical Research. Evaluation of the National Nutrition Anaemia Prophylaxis Programme. Task force study. New Delhi. ICMR, 1989.

[12] National consultation on control of nutritional anaemia in India. Department of Family Welfare (Maternal Health Division). Ministry of Health and Family Welfare, Nirman Bhawan, New Delhi, 1998.

[13] Seshadri S. A database on iron deficiency anaemia (IDA) In India: Prevalence, causes, consequences and strategies for prevention. Department of Foods and Nutrition. WHO Collaborating Centre for Nutrition Research. The Mahraja Sayajirao University of Baroda, Vadodara, India. 1999.

[14] Agarwal KN, Agarwal DK, Sharma K, et al. Prevalence of anaemia in pregnant and lactating women in India. Indian J Med Res 2006;124(2):173-84.

[15] Gautam VP, Bansal Y, Taneja DK, et al. Prevalence of anaemia amongst pregnant women and its sociodemographic associates in a rural area of Delhi. Indian Journal of Community Medicine 2002;27:157-60.

[16] IIPS National Family H 1998-99 (NFHS-2): httptfwww nfhsindia.org/ihdia2Mml: accessed on September 24, 2008.

[17] IIPS National Family Health Survey 2005-06 (NFHS-3): http./mohfw.nicin/nfhsfactsheethtm: accessed on September 24, 2008.

[18] DLHS on RCH. Nutritional status of children and prevalence of anaemia among children, adolescent girls and pregnant women 2002-2004. http:www.rchlndia.org/nrindia.htm 2006, accessed on September 24, 2008.

[19] Toteja GS, Singh P. Micronutrient profile of Indian population, New Delhi: Indian Council of Medical Research, 2004.

[20] National Nutritional Monitoring Bureau (NNMB) 2002. NNMB Micronutrient Survey, Hyderabad: National Institute of Nutrition. 2002. 
[21] WHO 2004. Micronutrient deficiency: battling iron deficiency: The challenge.

http//www.who.int/nut/ida.htm: accessed on April 24, 2008.
[22] Goli S, Rammohan A, Singh D. The effect of early marriages and early childbearing on women's nutritional status in India. Matern Child Health J 2015;19(8):1864-80. 